\title{
Options of medical treatment and laryngeal function preservation in elderly patients with medial wall pyriform sinus cancer
}

This article was published in the following Dove Press journal:

OncoTargets and Therapy

\author{
Qin Wang',2 \\ Yehai Liu' \\ Kaile Wu' \\ Yi Zhao' \\ Chaobing Gao' \\ Busheng Tong' \\ Ming Zhang ${ }^{3,4}$ \\ 'Department of Otolaryngology, \\ The First Affiliated Hospital of Anhui \\ Medical University, Hefei, People's \\ Republic of China; ${ }^{2}$ Department of \\ Otolaryngology, Hefei Second People's \\ Hospital, Hefei, People's Republic of \\ China; ${ }^{3}$ Department of Anatomy, Anhui \\ Medical University, Hefei, People's \\ Republic of China; ${ }^{4}$ Department \\ of Anatomy, University of Otago, \\ Dunedin, New Zealand
}

Objective: To retrospectively investigate the clinical efficacy and larynx preservation of two different treatments: radiotherapy followed by surgery $(\mathrm{R}+\mathrm{S})$ and surgery followed by radiotherapy $(\mathrm{S}+\mathrm{R})$, in elderly patients with medial wall pyriform sinus cancer.

Materials and methods: Medical records from 48 patients over 70 years old with medial wall pyriform sinus cancer who underwent different treatments between 2001 and 2010 were analyzed. Twenty-one patients underwent radiotherapy first followed by surgery $(\mathrm{R}+\mathrm{S})$, and the other 27 patients underwent surgery first followed by radiotherapy (S+R). A Kaplan-Meier method was used to calculate the survival rate.

Results: Overall 3-year and 5-year survival rates were $60.4 \%$ and $35.4 \%$, respectively. The 5-year survival rates in $\mathrm{R}+\mathrm{S}$ group and $\mathrm{S}+\mathrm{R}$ group were $38.1 \%$ and $33.3 \%$, respectively, without a statistically significant difference between the two groups $(P>0.05)$. Also, comparisons of the decannulation rates $(64.3 \%$ for $\mathrm{R}+\mathrm{S}$ group vs $50.0 \%$ for $\mathrm{S}+\mathrm{R}$ group) and postoperative complication rates ( $42.9 \%$ for $\mathrm{R}+\mathrm{S}$ group vs $37.0 \%$ for $\mathrm{S}+\mathrm{R}$ group) between the two groups of patients did not show obvious differences. However, the laryngeal preservation rates in $\mathrm{R}+\mathrm{S}$ group and $\mathrm{S}+\mathrm{R}$ group were $66.7 \%$ and $37.0 \%$, respectively, with significantly statistical difference between the two groups $(P<0.05)$.

Conclusion: Based on the data analysis of 48 patients, the survival rates of elderly patients who underwent $\mathrm{R}+\mathrm{S}$ or $\mathrm{S}+\mathrm{R}$ were comparable, but $\mathrm{R}+\mathrm{S}$ treatment could improve the laryngeal preservation rate of patients. Further study on large-scale sample pool should be performed to confirm this conclusion.

Keywords: medial wall pyriform sinus cancer, elderly patients, survival rate, larynx preservation

\section{Introduction}

Squamous cell carcinoma of the hypopharynx is a relatively uncommon malignancy, which accounts for $5 \%$ of all head and neck cancers and mainly occurs in males around 55 years old. ${ }^{1-4}$ Also, hypopharyngeal cancer is one of the most lethal malignancies of the upper aerodigestive tract, ${ }^{3,5}$ and more than $50 \%$ patients are diagnosed at advanced stage III and IV disease with locoregional and/or distant metastases, which is the main reason for its high mortality. ${ }^{6}$ About $70 \%$ of hypopharyngeal cancers are pyriform sinus cancer. ${ }^{7}$ Because the pyriform sinus lies outside the glottis, which is a relatively silent area, it allows tumors to grow before noticeable symptoms occur, ${ }^{8,9}$ and so there is only a small percentage of patients diagnosed at early stages of pyriform sinus cancer (stage I and stage II). Pyriform sinus cancer can spread laterally, medially, superiorly, or inferiorly in the submucosa. ${ }^{7}$ For lateral extension, the tumor
Correspondence: Yehai Liu

Department of Otolaryngology,

The First Affiliated Hospital of Anhui Medical University, 218 Jixi Road, Hefei, People's Republic of China Email liuyehai 123@163.com 
tends to invade the thyroid cartilage, cricoid cartilage, and thyroid gland. ${ }^{10}$ On the other hand, medial wall pyriform sinus cancer is usually associated with invasion of intrinsic laryngeal muscles. ${ }^{10}$ Therefore, it is more difficult to preserve the larynx for patients with medial wall pyriform sinus cancer than those with lateral wall pyriform sinus cancer.

For patients with early-stage medial wall pyriform sinus cancer, conservation surgery and definitive radiotherapy are the common treatment modalities. ${ }^{7}$ But for patients with advanced medial wall pyriform sinus cancer, radiotherapy followed by surgery $(\mathrm{R}+\mathrm{S})$ or surgery followed by radiotherapy $(\mathrm{S}+\mathrm{R})$ is more adopted. ${ }^{11}$ Different from young patients, elderly patients over 70 years old tend to suffer from a number of chronic diseases such as cardiovascular disease, lung disease, and diabetes, which make them less tolerant to operations and increase the preoperative or postoperative morbidity and mortality during the treatment. ${ }^{6}$ Therefore, total laryngectomy is still the mainstay treatment for elderly patients with advanced medial wall pyriform sinus cancer. ${ }^{6}$ However, total laryngectomy adversely affects the quality of life, especially for elderly patients since they need to communicate with others for assistance after treatment.

Our previous study showed that the survival rates of the hypopharyngeal cancer patients with or without larynx preservation were comparable, but larynx preservation could improve the quality of life of those elderly patients with hypopharyngeal cancer. ${ }^{6}$ In this present study, we aim to investigate the clinical efficacy of two different treatments $(\mathrm{R}+\mathrm{S}$ and $\mathrm{S}+\mathrm{R})$ on laryngeal preservation rate in elderly patients with specific medial wall pyriform sinus cancer.

\section{Methods}

\section{Patient characteristics and treatment}

The information of 48 elderly patients diagnosed with medial wall pyriform sinus cancer between 2001 and 2010 were obtained from the hospital records at The First Affiliated Hospital of Anhui Medical University, and details noted included patients' age, sex, cancer stage, treatment methods, postoperative complications, and survival. The survival rate was calculated from the start date of therapy in the hospital to the date of death. The patients received two different treatments, preoperative radiotherapy with surgery $(\mathrm{R}+\mathrm{S})$ and surgery with postoperative radiotherapy $(\mathrm{S}+\mathrm{R})$, based on their physical conditions and their will. This study was approved by the ethics committee of The First Affiliated Hospital of Anhui Medical University.

The detailed characteristics of all patients are listed in Table 1. A total of 48 patients aged 70-79 years old were enrolled in this study; among them, 43 were male and 5 were female. All patients were divided into two different groups based on the treatment: $\mathrm{R}+\mathrm{S}$ group had 21 patients and $\mathrm{S}+\mathrm{R}$ group had 27 patients. Based on the Hypopharyngeal Cancer Classifications Criteria, ${ }^{11}$ the patients were clinically classified with primary tumor stage I, II, III, or IV. Most of the patients were in advanced stages of medial wall pyriform sinus cancer: $3 / 48$ of patients were in stage $I, 8 / 48$ of patients were in stage II, 19/48 of patients were in stage III, and 18/48 of patients were in stage IV. Additionally, different surgical methods were used on different patients according to their status. The detailed information regarding surgical methods is also included in Table 1.

\section{Preoperative evaluation}

All patients received preoperative evaluation to assess their physical conditions, including examination of head and neck with laryngoscopy, tomography, and magnetic resonance imaging of the head and neck region. Among the 48 patients, 22 patients showed electrocardiography anomalous changes, 20 patients were diagnosed with hypertension, 15 patients had chronic bronchitis and emphysema, 8 patients had type-II

Table I Patient characteristics

\begin{tabular}{|c|c|c|c|}
\hline Characteristics & $R+S$ group $(n=2 I)$ & $S+R$ group $(n=27)$ & Total $(n=48)$ \\
\hline Gender (male/female) & $19 / 2$ & $24 / 3$ & $43 / 5$ \\
\hline \multicolumn{4}{|l|}{ Primary tumor stage } \\
\hline I & 2 & I & 3 \\
\hline II & 3 & 5 & 8 \\
\hline III & 9 & 10 & 19 \\
\hline IV & 7 & 11 & 18 \\
\hline \multicolumn{4}{|l|}{ Surgical method } \\
\hline Hypopharyngectomy & 6 & 5 & 11 \\
\hline Partial laryngectomy and hypopharyngectomy & 8 & 5 & 13 \\
\hline Total laryngectomy and partial hypopharyngectomy & 4 & 12 & 16 \\
\hline Total laryngectomy and hypopharyngectomy & 3 & 5 & 8 \\
\hline
\end{tabular}

Abbreviations: $\mathrm{R}+\mathrm{S}$, preoperative radiotherapy with surgery; $\mathrm{S}+\mathrm{R}$, surgery with postoperative radiotherapy. 
Table 2 ASA risk classification class and the comorbidity evaluation of the patients

\begin{tabular}{l|l}
\hline Cogent comorbid ailment & Encounters, $\mathbf{n}$ \\
\hline Electrocardiography anomaly & 22 \\
Hypertension & 20 \\
Chronic bronchitis and emphysema & 15 \\
Type-II diabetes mellitus & 8 \\
Sequelae of cerebral infarction & 4 \\
ASA class & \\
I & 11 \\
2 & 32 \\
3 & 5 \\
\hline
\end{tabular}

Abbreviation: ASA, American Society of Anesthesiologists.

diabetes mellitus, and 4 patients had sequelae of cerebral infarction. Nineteen patients had more than two types of diseases. According to American Society of Anesthesiologists (ASA) risk classification system, ${ }^{12}$ most patients were ASA class $2(32 / 48)$ whereas 5 patients were level 3 (Table 2).

\section{Operation method}

$\mathrm{R}+\mathrm{S}$ was performed in 21 patients and $\mathrm{S}+\mathrm{R}$ was performed in 27 patients. About 45-50 Gy was used for preoperative radiotherapy in $\mathrm{R}+\mathrm{S}$ group and followed by surgery at 30 days after the radiotherapy. The eligibility criteria for surgery after preoperative radiotherapy were determined by both patients' physical conditions and distant metastases. If the patients' physical conditions were normal and no distant metastases occurred, surgery was performed. If distant metastases occurred after the preoperative radiotherapy, patients received chemotherapy first, and so they were not included in our current study. For S+R group, 65-70 Gy was used for postoperative radiotherapy at 20 days after the surgery. The surgical methods used were as follows: hypopharyngectomy, partial laryngectomy and hypopharyngectomy, total laryngectomy and partial hypopharyngectomy, total laryngectomy and hypopharyngectomy. The tumor tissues were frozen after the operation for later employment in the repair operation after the confirmation of margin.

\section{Statistical analysis}

All the clinical data were processed and analyzed using SPSS 16.0 (SPSS Inc. Chicago, IL, USA). Kaplan-Meier method was used to identify survival rates and to compare the survival rates between the two groups. Statistical significance was defined as $P<0.05$.

\section{Results}

\section{Survival rate}

Among all patients, the 3-year and 5-year survival rates were $60.4 \%$ (29/48) and 35.4\% (17/48), respectively. For patients in $\mathrm{R}+\mathrm{S}$ group, the 3-year and 5-year survival rates were $57 \%(12 / 21)$ and $38.1 \%(8 / 21)$, respectively (Figure 1$)$. For patients in $\mathrm{S}+\mathrm{R}$ group, the 3-year and 5-year survival rates were $63 \%(17 / 27)$ and $33.3 \%(9 / 27)$, respectively (Figure 1). These results showed that no obvious differences in 3-year and 5-year survival rates were found in the two different treatment groups $(P>0.05)$. Further comparison of survival rates between patients with or without larynx preservation under $\mathrm{R}+\mathrm{S}$ or $\mathrm{S}+\mathrm{R}$ group is shown in Table 3. The data also indicated no significant difference in 5-year survival rates between patients with or without larynx preservation, which is in agreement with our previous study. ${ }^{6}$ For patients without larynx preservation, the 5-year survival rates were $42.9 \%(3 / 7)$ in $\mathrm{R}+\mathrm{S}$ group and $29.4 \%(5 / 17)$ in $\mathrm{S}+\mathrm{R}$ group. However, further analysis did not show any definite reason for this difference because one patient in the $\mathrm{S}+\mathrm{R}$ group died due to unknown cause.

Comparison of 5-year survival rates among patients with different clinical stages was also performed. The survival rates were as follows: stage I $66.7 \%(2 / 3)$, stage II $62.5 \%(5 / 8)$, stage III $31.6 \%(6 / 19)$, and stage IV $22.2 \%(4 / 18)$. These data showed that patients with early-stage cancer could achieve better curative effect than patients with late-stage cancer.

During the follow-up, 13 patients in the $\mathrm{R}+\mathrm{S}$ group died, including 4 with locoregional relapses, 4 with cervical lymph node metastases, 3 with distant metastases and 2 with locoregional relapses with distant metastases. For the $\mathrm{S}+\mathrm{R}$ group, 18 patients died, including 5 with locoregional relapses, 5 with cervical lymph node metastases, 4 with distant metastases, 2 with locoregional relapses with distant metastases, and 2 for reasons unknown. These results indicated that metastasis was the major cause of treatment failure.

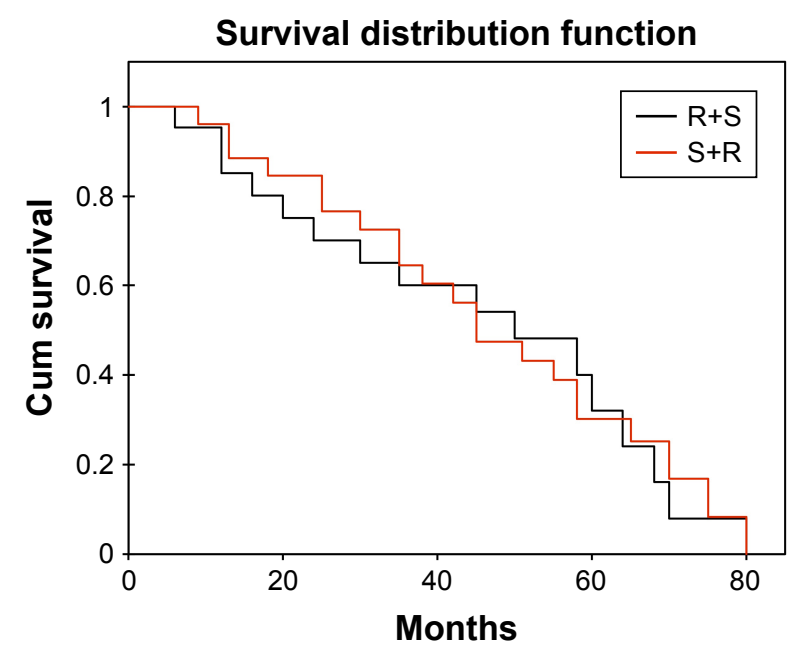

Figure I Survival rates of $\mathrm{R}+\mathrm{S}$ group vs $\mathrm{S}+\mathrm{R}$ group.

Abbreviations: $R+S$, preoperative radiotherapy with surgery; $S+R$, surgery with postoperative radiotherapy; Cum, cumulative. 
Table 3 Comparison of postoperative complication rate and 5-year survival rate between patients with or without larynx preservation in $\mathrm{R}+\mathrm{S}$ and $\mathrm{S}+\mathrm{R}$ groups

\begin{tabular}{|c|c|c|c|c|c|c|}
\hline \multirow[t]{2}{*}{ Survival } & \multicolumn{3}{|c|}{$R+S$ group $(n=2 I)$} & \multicolumn{3}{|c|}{$S+R$ group $(n=27)$} \\
\hline & $\begin{array}{l}\text { Larynx } \\
\text { preservation } \\
(n=\mid 4)\end{array}$ & $\begin{array}{l}\text { No larynx } \\
\text { preservation } \\
(n=7)\end{array}$ & Total & $\begin{array}{l}\text { Larynx } \\
\text { preservation } \\
(n=10)\end{array}$ & $\begin{array}{l}\text { No larynx } \\
\text { preservation } \\
(n=I 7)\end{array}$ & Total \\
\hline Postoperative complication & $6 / 14$ (42.9\%) & $4 / 7(57.1 \%)$ & $10 / 2 \mid(47.6 \%)$ & $4 / 10$ (40.0\%) & $7 / 17$ (4I.2\%) & I I/27 (40.7\%) \\
\hline 5-year survival & $5 / 14(35.7 \%)$ & $3 / 7(42.9 \%)$ & $8 / 21$ (38.1\%) & $4 / 10$ (40.0\%) & $5 / 17$ (29.4\%) & $9 / 27$ (33.3\%) \\
\hline
\end{tabular}

Abbreviations: $\mathrm{R}+\mathrm{S}$, preoperative radiotherapy with surgery; $\mathrm{S}+\mathrm{R}$, surgery with postoperative radiotherapy.

\section{Larynx preservation rate}

Among the 21 patients in the $\mathrm{R}+\mathrm{S}$ group, 14 patients preserved their laryngeal function successfully, leading to a larynx preservation rate in $\mathrm{R}+\mathrm{S}$ group of $66.7 \%(14 / 21)$. However, only 10 patients in $\mathrm{S}+\mathrm{R}$ group could preserve the laryngeal function, which resulted in only a $37 \%(10 / 27)$ larynx preservation rate in $\mathrm{S}+\mathrm{R}$ group (Figure 2). These results indicated that statistically significant difference $(P=0.042$, $P<0.05)$ in larynx preservation rates was found between patients receiving $\mathrm{R}+\mathrm{S}$ and $\mathrm{S}+\mathrm{R}$ treatment, and $\mathrm{R}+\mathrm{S}$ treatment could effectively increase the larynx preservation rate.

\section{Organ function}

In this study, 24 patients (14 patients in $\mathrm{R}+\mathrm{S}$ group and 10 patients in $\mathrm{S}+\mathrm{R}$ group) preserved their laryngeal function, and their laryngeal function in terms of swallowing, speaking, and breathing were assessed. The time taken to remove the stomach tube was 12-36 days, with an average of 15.3 days after treatment, and all the 24 patients could

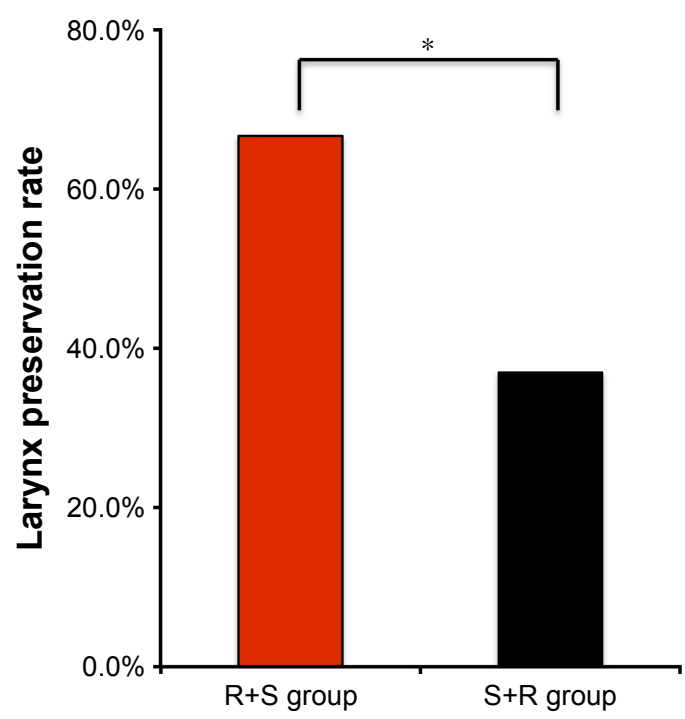

Figure 2 Comparison of larynx preservation rates between $R+S$ group and $S+R$ group.

Note: $* p<0.05$

Abbreviations: $\mathrm{R}+\mathrm{S}$, preoperative radiotherapy with surgery; $\mathrm{S}+\mathrm{R}$, surgery with postoperative radiotherapy. swallow normally without the assistance of feeding tube or gastrostomy feeding 3 months after treatment. With regard to phonation, all the 24 patients showed intelligible speech after the treatment, and no patients experienced dyspnea. Comparison of the decannulation rate between patients with larynx preservation in $\mathrm{R}+\mathrm{S}$ and $\mathrm{S}+\mathrm{R}$ groups did not show obvious difference ( $64.3 \%$ for $\mathrm{R}+\mathrm{S}$ group vs $50.0 \%$ for $\mathrm{S}+\mathrm{R}$ group). These results indicated that the preservation of larynx could improve the quality of life of patients, especially for the aged patients. The observation time for organ functions was 3-38 days, with an average 13.5 days after treatment.

\section{Postoperative complications}

The average postoperative hospitalization duration was 26.8 days, and there was no death during hospitalization. As shown in Table 4, 10 of 21 patients in the $\mathrm{R}+\mathrm{S}$ group experienced at least one postoperative complication: 4 cases of pharyngeal fistula, 1 case of dysphagia, 4 cases of abnormal deglutition, and 1 case of lung infection. Eleven of 27 patients in the $\mathrm{S}+\mathrm{R}$ group experienced at least 1 postoperative complication: 5 cases of pharyngeal fistula, 2 cases of dysphagia, 3 cases of abnormal deglutition, and 1 case of lung infection. No significant difference $(P>0.05)$ was observed between the $\mathrm{R}+\mathrm{S}$ and $\mathrm{S}+\mathrm{R}$ groups.

Further comparison of postoperative complication rates between patients with or without larynx preservation in $\mathrm{R}+\mathrm{S}$ or $\mathrm{S}+\mathrm{R}$ groups is shown in Table 3. The data also indicated that the postoperative complication rates between patients with or without larynx preservation were comparable.

Table 4 Postoperative complications in patients

\begin{tabular}{l|l|l}
\hline Complications & $\begin{array}{l}\mathbf{R}+\mathbf{S} \text { group } \\
(\mathbf{n}=\mathbf{2} \text { I) }\end{array}$ & $\begin{array}{l}\mathbf{S}+\mathbf{R} \text { group } \\
(\mathbf{n}=\mathbf{2 7})\end{array}$ \\
\hline Pharyngeal fistula & 4 & 5 \\
Dysphagia & $\mathrm{I}$ & 2 \\
Abnormal deglutition & 4 & 3 \\
Lung infection & $\mathrm{I}$ & $\mathrm{I}$ \\
\hline
\end{tabular}

Abbreviations: $R+S$, preoperative radiotherapy with surgery; $S+R$, surgery with postoperative radiotherapy. 


\section{Discussion}

As one of the most lethal malignancies of the upper aerodigestive tract, hypopharynx cancer is very difficult to be diagnosed at an early stage because its occurrence is latent and early symptoms are not noticeable. ${ }^{7}$ Most of the hypopharyngeal cancer occur in pyriform sinus, which accounts for $70 \%$ of all hypopharynx cancers. ${ }^{13}$ Based on the spread position, pyriform sinus cancer can be divided into medial wall pyriform sinus cancer and lateral wall pyriform sinus cancer. Because medial wall pyriform cancer is usually associated with invasion of intrinsic laryngeal muscles, it is more difficult to preserve the larynx of patients with medial wall pyriform sinus cancer. ${ }^{?}$

Different medical treatments can be used in the patients with medial wall pyriform sinus cancer based on their primary tumor stage. For patients with early medial wall pyriform sinus cancer, conservation surgery or definitive radiotherapy as the single treatment modality is common, which can yield get good curative effect without adversely affecting the quality of life of patients. ${ }^{7}$ However, for patients with advanced medial wall pyriform sinus cancer, a single treatment is not enough to achieve good treatment outcome. For example, the survival rate of treating advanced pyriform sinus cancer with only radiotherapy is merely $10 \%$, which is far below the $37.9 \%$ after comprehensive treatment. ${ }^{14}$ Therefore, comprehensive treatment is much more common for patients with late pyriform cancer. Based on the patients' status, comprehensive treatment can be preoperative radiotherapy followed by surgery or surgery followed by postoperative radiotherapy. The dose of preoperative radiotherapy is usually less than postoperative radiotherapy. ${ }^{15}$ Concurrent chemoradiotherapy is another common comprehensive treatment for patients with advanced pyriform sinus cancer. ${ }^{16}$ Primary chemoradiotherapy can achieve very good curative result in the majority of patients, but its failure results in poor functional outcome and late complications such as dysphagia and xerostomia. ${ }^{17-19}$ Induction chemotherapy followed by radiotherapy or induction chemotherapy followed by surgery and postoperative radiotherapy is another choice for patients with advanced pyriform sinus cancer. If the induction chemotherapy works well for patients, radiotherapy is effective as the following treatment. In the case of ineffective induction chemotherapy, the following treatment should include surgery followed by postoperative radiotherapy. ${ }^{20}$

Different from other cancers, management of pyriform sinus cancer requires the consideration of both survival and functional consequences of treatment, because the larynx function affects patients' swallowing, speaking, and breathing. ${ }^{6}$ It is relatively easy to preserve larynx in patients with early pyriform sinus cancer, but it still remains controversial for patients, especially elderly patients, with advanced pyriform sinus cancer. ${ }^{21}$ However, compared with young patients, it is even more important for aged patients to maintain the phonation function since they need more assistance after treatment. In our study, 17/37 elderly patients with advanced medial wall pyriform sinus cancer (stage III and IV) preserved their larynx successfully after treatment, which greatly improved their quality of life. Therefore, the preservation of laryngeal function mainly depends on the situation of tumor resection, the residual laryngeal tissue, and ASA classifications. T4 stage tumor is not a barrier to larynx preservation. But for aged patients who have very poor cardiopulmonary function or severe diabetes, deliberate preservation of laryngeal function is not recommended due to severe postoperative complications.

At present, to safely improve the larynx preservation rate of aged patients is one of the main goals for clinicians. Kirchner ${ }^{10}$ employed preoperative radiotherapy followed by total laryngectomy for 19 patients with pyriform sinus cancer. Postoperative detection confirmed that only ten samples contained tumor cells, five samples showed tumor cell apoptosis, and four samples showed no tumor cells, which verified that preoperative radiotherapy could effectively kill tumor cells..$^{10}$ In our study, we compared the survival rate among 48 patients who received preoperative radiotherapy followed by surgery or surgery followed by postoperative radiotherapy, and no significant difference was observed between these two groups. However, the larynx preservation rate in $\mathrm{R}+\mathrm{S}$ group was obviously higher than $\mathrm{S}+\mathrm{R}$ group $(66.7 \%$ vs $37 \%$ ). Hirano et $\mathrm{al}^{22}$ also found that preoperative induction chemotherapy could improve the larynx preservation rate. Therefore, for aged patients with advanced pyriform sinus cancer, preoperative radiotherapy can reduce tumor boundary, which increases the larynx preservation rate during operation. But in other researchers' opinion, preoperative radiotherapy decreased the healing ability of the surgery site, which increased postoperative complication rates. ${ }^{23}$ Our data did not show any obvious difference in postoperative complication rates between patients with or without larynx preservation in the $\mathrm{R}+\mathrm{S}$ or $\mathrm{S}+\mathrm{R}$ groups.

Although larynx preservation can improve the patients' quality of life, it should not be overrated. Saving the patient's life should be always the primary goal of a treatment strategy. The decision of treatment for each patient is very complex, and patient's physical conditions, the patient's will, and sometimes even the patient's financial situation need to be taken into consideration. Additionally, our present study 
selected only 48 patients, which is a small-scale sample, and so further study on large-scale sample pool should be performed to lead to more definitive conclusions.

\section{Conclusion}

Overall, based on our study of 48 elderly patients with medial wall pyriform sinus cancer, we found that the survival rates of these aged patients who underwent $\mathrm{R}+\mathrm{S}$ or $\mathrm{S}+\mathrm{R}$ were comparable, but $\mathrm{R}+\mathrm{S}$ treatment could improve the laryngeal preservation rate of patients. Further study on a large-scale sample pool should be performed to confirm this conclusion.

\section{Acknowledgment}

This study was supported by National Natural Science Foundation of China (81700898); Key Project of Health Commission Applied Medical Research of Hefei (hwk2016zd007); and Transfer Project of Hefei Science and Technology Bureau (YW201608080004).

\section{Disclosure}

The authors report no conflicts of interest in this work.

\section{References}

1. Hall SF, Groome PA, Irish J, O'Sullivan B. The natural history of patients with squamous cell carcinoma of the hypopharynx. Laryngoscope. 2008; 118(8):1362-1371.

2. Chang MF, Wang HM, Kang CJ, et al. Treatment results for hypopharyngeal cancer by different treatment strategies and its secondary primary - an experience in Taiwan. Radiat Oncol. 2010;5:91.

3. Prades JM, Schmitt TM, Timoshenko AP, et al. Concomitant chemoradiotherapy in pyriform sinus carcinoma. Arch Otolaryngol Head Neck Surg. 2002;128(4):384-388.

4. Tennant PA, Cash E, Bumpous JM, Potts KL. Persistent tracheostomy after primary chemoradiation for advanced laryngeal or hypopharyngeal cancer. Head Neck. 2014;36(11):1628-1633.

5. Samant S, Kumar P, Wan J, et al. Concomitant radiation therapy and targeted cisplatin chemotherapy for the treatment of advanced pyriform sinus carcinoma: disease control and preservation of organ function. Head Neck. 1999;21(7):595-601.

6. Wang Q, Liu Y, Hu G, Wang R, Zhao Y, Zhang M. The survival rate and larynx preservation in elderly cancer patients who received surgical operation: A retrospective cohort study. Int J Surg. 2016;36(Pt A): 342-346.

7. Krstevska V. Early stage squamous cell carcinoma of the pyriform sinus: a review of treatment options. Indian J Cancer. 2012;49(2):236-244.

OncoTargets and Therapy

\section{Publish your work in this journal}

OncoTargets and Therapy is an international, peer-reviewed, open access journal focusing on the pathological basis of all cancers, potential targets for therapy and treatment protocols employed to improve the management of cancer patients. The journal also focuses on the impact of management programs and new therapeutic agents and protocols on

Submit your manuscript here: http://www.dovepress.com/oncotargets-and-therapy-journal
8. Elias MM, Hilgers FJ, Keus RB, Gregor RT, Hart AA, Balm AJ. Carcinoma of the pyriform sinus: a retrospective analysis of treatment results over a 20-year period. Clin Otolaryngol Allied Sci. 1995;20(3): 249-253.

9. Sewnaik A, Hoorweg JJ, Knegt PP, Wieringa MH, van der Beek JM, Kerrebijn JD. Treatment of hypopharyngeal carcinoma: analysis of nationwide study in the Netherlands over a 10-year period. Clin Otolaryngol. 2005;30(1):52-57.

10. Kirchner JA. Pyriform sinus cancer: a clinical and laboratory study. Ann Otol Rhinol Laryngol. 1975;84(6):793-803.

11. Patel SG, Shah JP. TNM staging of cancers of the head and neck: striving for uniformity among diversity. CA Cancer J Clin. 2005;55(4): 242-258.

12. Ferrier MB, Spuesens EB, Le Cessie S, Baatenburg de Jong RJ. Comorbidity as a major risk factor for mortality and complications in head and neck surgery. Arch Otolaryngol Head Neck Surg. 2005;131(1): $27-32$.

13. Steiner W, Ambrosch P, Hess CF, Kron M. Organ preservation by transoral laser microsurgery in piriform sinus carcinoma. Otolaryngol Head Neck Surg. 2001;124(1):58-67.

14. Johansen LV, Grau C, Overgaard J. Hypopharyngeal squamous cell carcinoma - treatment results in 138 consecutively admitted patients. Acta Oncol. 2000;39(4):529-536.

15. Spector JG, Sessions DG, Emami B, et al. Squamous cell carcinoma of the pyriform sinus: a nonrandomized comparison of therapeutic modalities and long-term results. Laryngoscope. 1995;105(4 Pt 1):397-406.

16. Pignon JP, le Maître A, Maillard E, Bourhis JMACH-NC Collaborative Group. Meta-analysis of chemotherapy in head and neck cancer (MACH-NC): an update on 93 randomised trials and 17,346 patients. Radiother Oncol. 2009;92(1):4-14.

17. Cmelak AJ, Li S, Goldwasser MA, et al. Phase II trial of chemoradiation for organ preservation in resectable stage III or IV squamous cell carcinomas of the larynx or oropharynx: results of Eastern Cooperative Oncology Group Study E2399. J Clin Oncol. 2007;25(25):3971-3977.

18. Langendijk JA, Doornaert P, Verdonck-de Leeuw IM, Leemans CR, Aaronson NK, Slotman BJ. Impact of late treatment-related toxicity on quality of life among patients with head and neck cancer treated with radiotherapy. J Clin Oncol. 2008;26(22):3770-3776.

19. Terrell JE, Fisher SG, Wolf GT. Long-term quality of life after treatment of laryngeal cancer. The Veterans Affairs Laryngeal Cancer Study Group. Arch Otolaryngol Head Neck Surg. 1998;124(9):964-971.

20. Lefebvre JL, Andry G, Chevalier D, et al. Laryngeal preservation with induction chemotherapy for hypopharyngeal squamous cell carcinoma: 10-year results of EORTC trial 24891. Ann Oncol. 2012;23(10): 2708-2714.

21. Marioni G, Marchese-Ragona R, Cartei G, Marchese F, Staffieri A. Current opinion in diagnosis and treatment of laryngeal carcinoma. Cancer Treat Rev. 2006;32(7):504-515.

22. Hirano S, Tateya I, Kitamura M, et al. Ten years single institutional experience of treatment for advanced hypopharyngeal cancer in Kyoto University. Acta Otolaryngol Suppl. 2010;563(563):56-61.

23. Wennerberg J. Pre versus post-operative radiotherapy of resectable squamous cell carcinoma of the head and neck. Acta Otolaryngol. 1995; 115(4):465-474.

\section{Dovepress}

patient perspectives such as quality of life, adherence and satisfaction. The manuscript management system is completely online and includes a very quick and fair peer-review system, which is all easy to use. Visit $\mathrm{http}: / /$ www.dovepress.com/testimonials.php to read real quotes from published authors. 